\title{
Motivation and Learning Strategies in a Foreign Language Classroom A Look at Learners of Saudi Arabia
}

\author{
Shahinaz A. Bukhary \\ Lecturer, English Language Institute, King Abdulaziz University \\ P.O. Box 42770, Jeddah, 21551, KSA \\ Tel: 00966555684171 E-mail: sbukhary@kau.edu.sa \\ Dalal A. Bahanshal (Corresponding author) \\ Lecturer, English Language Institute, King Abdulaziz University \\ P.O. Box 80203, Jeddah, 21589, KSA \\ Tel: 00966505684068 E-mail: d.bahanshal@gmail.com
}

Received: 31-05-2013

doi:10.7575/aiac.ijalel.v.2n.5p.192
Accepted: 07-07-2013

Published: 01-09-2013

URL: http://dx.doi.org/10.7575/aiac.ijalel.v.2n.5p.192

\begin{abstract}
Motivation is a fundamental factor to fructify any functional and effective classroom setting with interest, hope and expressive fruitful teaching experience. Motivating foreign language learners to advance successfully in learning the target language (English) is a domain that has been discussed widely in many language learning studies. In fact, there is still much argumentation on to what extent motivation influence language learning as there is not clear evidence of how motivation manipulates the success or failure of the target language. It is noticeable that language learners, in this case Saudi university students, do not invest as much time in learning English as they do in learning their specialist subjects. This paper tends to look at the meaning of motivation and how far does it go to affect language learning. It also attempts to investigate factors that frustrate learners by conducting different research tools such as interviews and questionnaires for both English students and instructors. Research results present that many students dislike English classes and wish not to participate or attend them. Additionally, teachers comment that despite the efforts to promote language learning, the outcome of their students is considered to be unsatisfactory. Teachers believe that this can be contributed to the fact that they are pressed to complete fixed curriculum in a limited period of time and abide by strict instruction to evaluate their students with no room left for them to personalize their own learning experience. Therefore, teachers need to be given opportunities to broaden their pedagogical repertoires and make English learning more engaging and more meaningful. The study implications shed the light on some useful hints to be applied in EFL classes.
\end{abstract}

Keywords: motivation, language learning, EFL classroom and learners, Saudi Students

\section{Introduction}

Due to its enormous popularity, English language is used in many areas of human interaction. Accordingly, it has made its way into the curriculum of a large number of academic institutions all over the world. Dalby comments "no one can doubt that the use of English worldwide is growing year by year, as is the demand for English language teaching" (2002: 10). As a result of the high demand for English learning, most schools and institutions of higher education all over the world have developed many programs to teach it. One country where English is learnt as a foreign language is Saudi Arabia. Saudi Arabia is taking an important part in the world and engaging a critical role in politics and commerce. To reinforce its evolution and development, it needs to be engaged in international dialog at all levels. Considering the position of English worldwide, the Saudi government has focused on increasing its proficiency at all levels of education. Therefore, teaching English as a foreign Language has been made mandatory at schools and higher education institutions. However, the quality of English learning among Saudi learners is abysmal. Even after years of studying, most students are unable to communicate in English, and have only the most basic reading and writing skills.

In this paper, which is an expansion of a recent research regarding motivating university students in EFL classroom at Lebanese American University in Lebanon (Bahous, Bacha, \& Nabhani, 2011), we plan to look at motivation in relation with EFL learning in formal Saudi university classroom as motivation considers to be a potent factor in learning the target language. It is also researchers' aim to examine factors of success or failure of English learners in regard with their level of motivation with the ultimate goal of offering recommendations to design curriculums that could enhance students' motivation towards English learning. Our expectation is that these recommendations will eventually improve language programs in Saudi universities.

The study of motivation in relation with EFL teaching and learning in many formal classrooms drives researchers to consider the important factors which are involved in the learning and teaching process such as EFL learners, instructors, syllabus and learning pedagogy. Crookes and Schmidt (1991) identified motivation as the learner's orientation with 
regard to the goal of learning a new language. Gardner (1985) also defined it as the extent to which an individual works or strives to learn the language because of a desire to do so and the satisfaction experienced in this activity. Therefore, motivation is known to be a complicated psychological process which begins as a need of something and then leads to actions and manners that aid people to fulfill their aims (Melendy, 2008). In words, it is one important factor that elevates humans' enthusiasm, readiness and desires to try and learn new things and that of course, correspond to English learning as well.

Dornyei confirms that to motivate EFL learners in classrooms a great number of psycho-sociological and various linguistic factors must be engaged in the learning process (2010a). That is to say motivation is to be highly valued in classrooms but is powerful when language teachers create variable methods which meet learners' objectives and their private needs (Hedge, 2000; Taguchi, 2002; Gangwer, 2009). It is believed that all what are done in EFL classrooms are likely to promote reduce or preserve learners' motivation. Therefore, motivation requires to escort both teaching and learning styles which serve the different needs of all learners with consideration to certain issues such learners' political, private, public and professional language needs. What appears to be interesting is that, it is the learners' goal to involve in certain activities without being bored or distracted that can make instructors conclude that their students are extremely motivated.

\subsection{English in Saudi Arabia}

In regard with language learning, this section commences by shedding the light on the position of English in Saudi Arabia as well as looking briefly at the Saudi education system. For its significance on political communication and both social and technological development, English language is considered to be one of the most important subjects that Saudi students have to learn and yet master. Recently, English becomes the medium of instruction in all Saudi universities. In addition, English mastery becomes a prerequisite for acceptance in King Abdullah Scholarship Program. It is also a substantial step for many Saudis to qualify them to earn a superb position in the Saudi job market which can be described as highly competitive as the interest in getting a job or finding a good one with a high salary is highly popular.

At present, teaching and learning English in Saudi Arabia is counted to be a challenging task for both learners and teachers. The challenges have called for quick intervention form decision makers and material developers at The Saudi Ministry of Education to put their efforts together to provide Saudi learners with ample materials along with different strategies to learn and master English as a foreign language. English teaching begins in Saudi Arabia at school level. Public and private education in Saudi Arabia, which is available for both boys and girls, has three levels; elementary (grade 1 to 6), intermediate (grade 7 to 9) and secondary (grade 10 to 12). English teaching starts at grade 6 then continues till grade 12. During their seven years of studying, students learn all English skills, writing, speaking, listening and reading along with other aspects as grammar and vocabulary. Curiously enough after this long period of learning and regardless to the comprehensive program, curriculum design and trained teachers, students still fumble when using English not only in public but also in classroom context. This line of difficulty catches the attention of some researchers who have conducted some diagnostic studies to detect the type of problems and the corresponding factors that either hinder or elevate English language learning in Saudi Arabia.

As a matter of fact, students' motivation to learn English in Saudi Arabia has to do with their desire to participate in the learning process. But it also concerns the reasons or goals that underlie their involvement or noninvolvement in academic activities. Even though, students may be equally motivated to perform a task, the sources of their motivation to learn English may differ. Therefore, diagnostic studies should better be undertaken in different language areas so that Saudi English teachers may know the types of problems and the corresponding factors their students encounter while learning. Such attempts are expected to be helpful in possible evolution of some fruitful and compatible strategies in order to yield the maximum academic output.

The main aim of this study is to examine the role of motivation in English language achievement among Saudi university learners across four Saudi universities. The continued complaint of lack of motivation, boredom, and lack of good English learning environment has called for concern on how to arouse learners' motivation. It is essential then to benefit from studies that tackle motivation factors and utilize their results to the Saudi educational context.

\subsection{Significance of the Study}

It is our anticipation that this study will contribute to our understanding of the role of motivation on English learning in Saudi Arabia through investigating different factors that affect students' motivation and then recognizing obstructions and difficulties Saudi learners experience during their long and hectic journey in English learning.

\section{Literature Review}

\subsection{Motivation and Language Learning}

While studies on motivation have tackled the issue from a variety of viewpoints, the focus is seemingly on finding a relationship between motivation and language learning. Through many studies, there is a widespread recognition that motivation is of great importance for successful foreign language learning (Ajibade \& Ndububa, 2008; Guilloteaux \& Dörnyei, 2008; Melendy, 2008; Wu \& Wu, 2008; Feng \& Chen, 2009). These studies and many more have asserted that motivation is undoubtedly an important factor in foreign language learning success. It is perhaps Grander and his associates who have devoted the greatest attention to the topic of motivation and provided the most notable amount of information on regards to the different factors that affect foreign language learning (Gardner \& Lambert, 1972; Tremblay \& Gardner, 1995). 
Finding definitions to clarify the term motivation tends to be complex. In words, motivation is manipulating, inspiring, and persuading learners in a way to advocate and boost their professional aims. Brown defines motivation more pragmatically as 'the extent to which you make choices about (a) goals to pursue and (b) the effort you will devote to that pursuit' (2007: 85). Zhou (2009), on the other hand, confirms that motivation is synonyms with 'student voice' that is in the presence of locating one's learning in the present moment, it is potential for EFL learners to view learning in effective and significant way.

Another further interesting point is mentioned by Harmer (1991) who agreed that motivated students perform considerably better than others in class regardless of their teachers' unsatisfactory methods while students who are less motivated with good learning abilities will not be able to achieve their goal. Such demotivation can result in students' low achievements or negative attitudes toward the target language. Therefore, researchers, material developers and teachers consider motivation as one of the key factors influencing language success. As language teachers, we have to recognize the significant part motivation plays on our students' learning and understand its concept in order to reinforce learners' outcome.

All in all, a better understanding of students' motivation may aid course designers and language teachers to innovate language programs which generate the motivation most conducive to the production of more successful English learners. For such goal, many studies have been conducted worldwide to investigate this significant phenomenon in language learning. An old study which was carried out in Malaysia among some university students revealed that university students were integratively and instrumentally oriented towards English learning (Vijchulata \& Lee, 1985). A recent study investigates the influence of motivation on language learning on a sample of 75 empirical studies.

The result shows that motivation is significantly connected to learning achievements (Masgoret and Gardner, 2003). Considering English learning among Arabs, a certain number of studies have been undertaken to explore learners' attitudes and motivation toward English learning. Qashoa (2006) conducted a study in Dubai that aims to investigate the instrumental and integrative English motivation of secondary school students and hence to recognize factors influencing learners' motivation. The finding shows that learners have a higher degree of instrumentality than integrativeness. It also confirms that difficulties learners encounter with English aspects such as spelling words, memorizing vocabularies or forming correct sentences tend to be the most demotivating factors for students.

In the Saudi context, Al-Maiman (2005) carried out a study to investigate the motivation level of Saudi English learners before and after and they were exposed to English in a formal classroom learning setting. The study was based on a qualitative data where 301 seventh-grade students answered 54 questionnaire items written in Arabic. The finding is very interesting as it reveals that students have high motivation to learn English before they experienced learning it formally.

\subsection{Classroom Motivation}

As mentioned earlier, students' motivation is still an area which many researchers intend to tackle as they believe that without ample motivation, even students with high abilities may not be able to obtain their goals either on a short or a long term. Lumsden (1994) confirmed that it is a great challenge for teachers as well as parents to maintain students' interest and motivation to succeed as many students are not sufficiently motivated. For that, many researchers have counted on teachers and classroom activities to stimulate learners' motivation level. They believe all that occur in classroom are likely to boost, minimize or ensure learners' motivation. In words, it is the tasks which are carried out in classrooms, the methodology that are being followed as well as the ways instructors and learners use to communicate together and other factors will have great impact on learners' motivation. $\mathrm{Wu}$ and $\mathrm{Wu}(2008)$ believe that positive and easy classroom environment correlate students' motivation with language success.

This line of reasoning receives some support from researchers and course designers who believe that teachers must prompt their students to be active members in classes as their duty to implement entertaining activities and use interesting texts which gain students' attention and then help to increase their level of motivation in classroom. Active engagement, as such, in classroom activities helps students to sense the purpose of developing their language skills.

What appears to be interested is that some students in some EFL classroom are either frightened or elusive to communicate for fear of making errors. That is to say, nothing is more thwarting for students than to be obsolete, abandoned or negligently estimated, or to feel that their work does not meet their teacher's standard. Research in this area suggests that positive feedback nudge classroom environment toward change. Therefore, it is the teacher's role to urge students to converse and debate using the target language and praise their performance and progress, no matter how limited it may be. This encouraging attitude will create a pleasant atmosphere, motivate students and make English classes lively and enjoyable. It is inevitable that praising and rewarding students positively impact classroom learning as they lower students' anxiety and increase their self-confidence and motivation. Thus, an encouraging attitude in the part of the teacher motivates students and makes them interested in learning the language. Feng and Chen stress the importance of teacher's personality for learning "An enthusiastic and considerate teacher can offer satisfaction to the learner's extra needs. This helps strengthen the learner's study motivation" (2009: 64). It is more likely that language learning will thrive if teachers stimulate their students, encourage learning independency, affirm self study and enforce the use of technology. A classroom environment as such will reflect positively on learners' achievement.

Another interesting strategy that can elevate the level of motivation is communicating in the target language. Teachers can employ communicative approach to facilitate motivation and then lead to a successful learning environment. Ebata (2008) points out that motivation produces effective learners who are willing to use the target language to communicate with great self confident. 


\section{Method}

\subsection{Aim of the study}

The study aims here were twofold: (1) to determine what the motivations of university students towards learning English as foreign language are like in some Saudi language institutions of higher education; (2) to look at the opinion of both students and teachers about factors which contribute to ineffective interacting in EFL classes and moreover to master the target language. The present study is expected to be useful for university language instructors in possible improvement of some fruitful and appropriate methods in order to yield the utmost learning output.

\subsection{Research Site}

The site where this study is undertaken is at English language institutions inside the campus of four Saudi Universities. Historically speaking, English came in the Saudi curriculum in 1950s in grades 7 - 9 then to grade 12 (Al-Shamary, 1984). Recently, teaching English starts at grade 4. Giving more importance to English reflects the concern of the decision maker at the Ministry of Saudi Education. At the university level, students at the foundation year must take four obligatory general English courses unless they are exempted from some or all courses depending on their achievement on the English placement test at the beginning of their enrollment academic year. It is worth mentioning that the university evaluation guidelines establish that students take two English computerized tests per module, mid and final exam. The tests focus on listening, grammar, vocabulary and reading while writing is conducted within the module.

\subsection{Participants}

\subsubsection{English Learners}

The research data was collected from Saudi English learners studying and teachers teaching at four Saudi universities. The selection of participants is vital for the success of the research. Hatch and Farhady stated that "subject selection may influence the results of research studies" (1982: 8). Randomly, one hundred and twenty students who are attending different general English courses at the largest Saudi universities were invited to participate. Eighty out of one hundred and twenty students accepted to join the study. The eighty students were recruited through personal contact. The participants mentioned that they have studied English in order to be successful in their future education and career.

\subsection{Instructors}

Fifty language instructors who are teaching at the same four universities were invited to engage in the questionnaire survey. Instructors provide massive contributions to the study results as the students' learning outcomes are influenced by teachers whose perceptions toward motivation has a great impact on the usefulness of learning. Thus, semi-structured questionnaires were emailed to instructors teaching in the selected Saudi universities. Among all, only thirty four instructors responded.

\subsection{Procedure and Instruments}

To understand how and to what extent motivation facilitated EFL learning, a qualitative research methodology was used as it is interested on people as the tool of inquiry. It also consists of information that is more holistic because it focuses on observation, interviews and surveys. Interestingly, it is therefore needed to provide deep understanding to the factors affecting students' motivation. This study has mixed methods of questionnaires and semi-structured interviews which are used on regard with the literature review on motivating English learners. Yin (1994) considered interviews to be "one of the most important sources of case study information" (p. 84). Among the different kinds of interviews, both interviews conducted in this study, individually and face to face, were semi-structured to encourage interviewees to talk in an open-ended manner, with focus on the topic presented, and to provide freedom and litheness to interviewees to express their experience and problems with English learning. Interviews (see Appendixes A \& B) let the researchers comprehend the phenomenon of learning desire through the interviewees' points of view not as the researchers might perceive it.

The other method used here is questionnaires which are defined by Brown as "any written instruments that present respondents with a series of questions or statements to which they are to react either by writing out their answers or by selecting from among existing answers" (2001: 6). Even though, questionnaires' objectives were to interrogate participants' changeable views, the study was not conducted descriptively but qualitatively to deduce data from the participants' perspectives as it was not likely to attain holistic conclusion in a descriptive study. Furthermore, notes on the open conversation and meetings, held on the premises of the research site, as well as off the record marks mentioned by both students and teachers about English learning were written down. Engrossed in reading the transcripts many times, allow the researchers to jot down carefully all concerted themes and observation of all participants. Doing that, the researchers' intention was to be intimately familiar with the data (Marshall \& Rossman, 2006).

The researchers were quite aware that the research might have some strengths and weaknesses related with each type of the data. Thus, the diverse sources of data acted to supplement each other. It was the researchers' part to ensure authenticity, suitability and reliability of the results. To do this, the researchers administered two kinds of qualitative data. First, extract interviewees' answers then analyze them in terms of themes related to the study objectives. Second, anatomize questionnaires which provided significant information to the research findings.

\section{Results}

\subsection{Aim of English of classes}

Thirty seven students who are studying in universities which don't support English courses with some English for special purpose (ESP) materials believe that English language courses don't facilitate their learning with other university subjects and don't develop the language they need in their majors and future careers. Forty seven participants comment 
that their teachers give more attention to grammar than other language skills. One student said "I study English to improve my self-confidence". Five students stated "good job offers are available for people who can speak English fluently". Fifty three students think that English courses should be obligatory while eighteen wish for English to be set as an elective course rather than a perquisite. Nine students wish for English to be removed from the university curriculum. It is also strongly suggested by seventy six students to have ESP materials integrated in the university courses.

The findings from the teachers' questionnaire reveal that twenty nine teachers believe that grammar and listening are the most important skills Saudi learners need in beginner classes since most of the students can't form complete sentences correctly and can't pronounce words fluently. Seventeen instructors confirm that reading and writing are very important to elevate students' academic level thus their part is to facilitate the learning of these two skills.

\subsection{Content and Teaching Methods}

One of the most important factor that motivate students to learn the language is the material presented to them in class that meets their interest and have authentic relation to their outside world. Failing to meet their attention, twenty four students clearly mentioned that "text books of general English classes are boring". One student said: "I hate this course because it doesn't present something new". Three students declared "we will be motivated to attend English courses if they are related to our life and future career". Six others asserted "we become more willing to study English when the teacher gives us the chance to show our creativity". Eleven students affirmed that "we feel disappointed when the lecturer repeats explaining the grammatical structures again and again". Thirteen students reported that "our class is motivated when our English instructor invites us to talk freely and gives us practical assignments".

As a respond to the question set for the teachers in regard to the most significant method that help learners debate and argue interactively using English, they said that discussing themes which have culture values, creating relevant activities, arranging work groups, and rewarding students are different techniques that encourage the language use. Additionally, English instructors were questioned to highlight the utmost significant plans that facilitate the learners critical believe towards the learnt language, their responds were asking indirect questions, focusing on conclusions, giving the opportunity to express opinions, requesting evidences to support ideas, and giving relevant assignments. Interestingly, some English instructors comment that students are unmotivated to attend English classes or take part in discussion and activities because instructors are not allowed to evaluate their students' participation and class work and students are only evaluated by unified exams. The vast majority of instructors complain that they can't convert to interactive teaching methods because they are pushed by limited time and have to follow very strict pre-structured syllabi without having any room to personalize their own teaching process.

\subsection{Language Skills}

Based on information brought to light by English instructors on the potential issues that impede learners from mastering the target language, the shortage of impetus consequent to various factors was the main problem. University teachers have pointed out that students leave secondary stage with no ability to carry out a short conversation. Six instructors justified their focus on grammar "because our students can't form a complete sentence correctly". Most students who enter university after studying English for seven years are not able to comprehend instructions or read references in English. According to them, another problem that Saudi learners face is that they use their native language at home and during their interaction with friends, and classmates. When asking students about their perceptions of using English outside the classroom with friends, patents or others who they meet daily in shops and restaurants, ten students mentioned that "we can't practices English in our society because people will think that we are showing off our English". Consequently, there is a bleak chance to learn English through day-to-day interaction. Instructors also asserted that the pervading displeasure with the overall output of Saudi students in learning English was a cause of poor essential principles in curriculum conception and design, insufficient in classroom approaches, boring topics with little relation to learners' real life and the intensive concentration on grammar rather than speaking or listening.

Furthermore, majority of the students, about forty seven, mention that they encounter difficulty expressing their selves contentedly and competently either when faced with scholarly subjects or usual everyday issues. Others affirm that their low proficiency in English is due to the reason that they don't study English at early stages and eventually don't use English as a medium of instruction except in certain higher education courses. Furthermore, half of the participants indicate that their teachers' main concern is to teach grammar leaving other skills for students self study. Other complains that class language is so formal and doesn't consider the contexts that preserve a high priority on communicative success. They also mention that their teachers mostly dominate the class leaving no option for them to exchange ideas with the teachers, answer and ask questions as asking a question is viewed to be a lack of knowledge. Almost all agree that English topics are neither linked to their authentic life nor to the majors they wish to study at university. They recommend that curriculum designers must pay more attention to reading and speaking skills and to apply communicative approach as well as considering teaching ESP in the foundation year. Lastly, learners were questioned about their aims of learning English, their respond is English is an instrumental tool that aids our goal achievements to either higher study outside Saudi Arabia or to an eminent career.

\section{Discussion}

Researchers have gleaned from the review of some of the recent literature and some of their own devising that understanding how motivation affect language learning might benefit materials developers, teachers and language learners. A focus on motivation and enjoyment in materials will aid in shaping motivating learning contexts 
(Guilloteaux \& Dörnyei, 2008). For example, the difficulty level of materials is an important factor that needs attention, because very difficult or very easy tasks might create the sense in students that they are either incompetent or that they are not adding to their knowledge. In either case, because students cannot satisfy their need to learn more, they might feel unmotivated.

English instructors and learners alluded to their frustration towards English teaching and learning in Saudi universities. Although Saudi government has made great efforts to improve English skills in schools and universities, English learning still a serious problem. The prevalence of the loss of motives and interest in Saudi learners is adversely affecting language learning. Generally speaking, learners have no interest in learning the language and seemingly don't realize its significance. Therefore, we cannot dispute the fact that motivation is an important variable when examining the success of English language learning. Beck (2004) suggests that motivation is derived from the Latin verb "movere" that means "to move". Thus, motivation is accountable for our actions, attitudes and in the way our conducted manners.

Dörnyei (2005), comments that teacher motivation is a significantly positive factor in students' learning and achievement. However, he proposes that teaching is a profession with special characteristics but has received little attention in educational psychology. In regard to the different domain language teachers in general and EFL teachers in particular are working in, Dörnyei also recommends that teachers must receive special attention to elevate their motives and enthusiasm. They need to be offered distinguished training to expand their knowledge and exchange their experience which is required in this period of swift development.

To reinforce learners' motives in classes, teachers, can use puzzles of different level of challenge, address questions that place learners into a problem-solving mode and relate instructional material to topics already of interest to learners. The outcome of such interesting classes and challenging materials is of a great influence on learning. On the contrary, when the challenge of assignments is high and skills are low, psychological state of anxiety is the result. A feeling of boredom is an output if challenges are low and skills are high, and a negative state of apathy appears when both challenges and tasks are low. What appears necessary is that learners and their teachers have to adapt interesting, challenging, authentic and real life learning engagements to make English learning setting factual, genuine and purposeful. It is the students' recommendation for ESP to be merged with meaningful subjects that are in relation with their outside world. They also recommend that subjects' content must be opted in regard with their values and culture as most Saudi learners find the cultural values of the target language community to be alien.

One important issue students spoke of is that speaking activities are limited and classes do not utilize the interactive teaching as they are teachers-centered rather than learners-centered. Researches have repeatedly demonstrated that teachers do approximately much of the talking in classrooms leaving no space or little for students to debate through practicing and using the language as a mean of communication. Roberts defined language as "the system of speech sound by which human beings communicate with one another" (1958: 18). Language is also viewed as a vehicle for communicating meaning and messages (Richard \& Rodgers 1992). In short, human use words and phrases in interactive process of constructing meaning of speaking. Hence, speaking is making use of language in ordinary voice; uttering words; knowing and being able to use a language; expressing oneself in words; making speech. Therefore, speaking can be as the way to carry out feeling through words. It is then important for teachers to be percipient of how much they talk in class and not to take up all the time students could be talking. Pair and group work activities can be applied to boost the amount of time that learners get to speak in the target language during lessons.

In recent studies, Davis (2003), Yang \& Lau (2003) and El-Dib (2004) detect that learners respond positively in communicative settings rather than instructional ones as interactions with peers and teachers promote their leanings. For teachers to adjust class environment to benefit the most from the learning process to acquire the language, a careful consideration must be given to the quality of the input they offer to their students as frequent exposure to the language allows learners to notice the correct and appropriate use of words and structures.

One further interesting point some teachers recall is that they encounter difficulties to cater various teaching strategies as they have to abide by the time limit of the curriculum which holds them back from enforcing communicative approach in their classes (Morell, 2004). Not only that, but some university English instructors don't have the authority to evaluate their own students, and cannot reward or threaten students by grades which are considered a motivating factor in the educational process. It is believed that, students' assessment and evaluation create a prominent remark between learners of high and low level of language proficiency (Marshall \& Weinstein, 1986). Therefore, teachers must be given authority to assess, evaluate and reward their students and that will utilize students' engagement in classroom and then prompt their language achievement.

To this end, it is worth noting that all the above mentioned strategies should be in harmony since even applying most of them might not guarantee the progress and the success if learners are not disposed to learn.

\section{Reflections and Implications}

No study is complete by itself and cannot take every detail into consideration. Therefore, there are always aspects which are not accounted for. This research is no exception. There are some issues which were not controlled in this study and can be topics for further research. The data from teachers and students questionnaires and interviews identifies some problems in language classes at Saudi universities which recommend deep discussion. Interestingly, as the study unfolded, we found that the state of English teaching in Saudi Arabia is not up to the mark and learners are not motivated to make any effort to develop their language skills. This conclusion is borne out in the words of the participants who stated that the uninteresting materials used in non-interactive classes, concentrated grammar lessons and lack of linkage between materials taught and their majors or future careers hinder their language improvement. 
Students request designing course topics and materials that are in great rapport with their real life and that, according to students, might in turn enhance the effectiveness of classes. They also stress on giving more attention to speaking and writing along with teaching grammar rules.

On the other hand, language instructors allude that students have no interest in learning the language and tend to be demotivated. They suggest that the more effective and interesting topics are presented in EFL classes, the less demotivated students will be. Therefore, efficient solutions ought to be considered to provide appropriate teaching setting to flourish language learning. Another factor teachers mention which leads to a lack of motivation is that some universities do not allow teachers to evaluate their students' class work and participation where students are evaluated only by unified exams once or twice each term. Other teachers indicate that they are not able to switch from the teacher-centered classes to interactive teaching as they are hardly pushed by the course time limit and design. All in all, EFL instructors always complain about unmotivated students and the obligation to follow very strict pre-structured syllabi without having any room to personalize the learning process.

Taken together, teachers have to be well equipped, and make diagnostic study in order to analyze the nature and type of difficulties students encounter during their study. It is also recommended to actively encourage teachers to keep abreast with language developments, and to foster teacher independence in classroom. By doing so, it is expected that teachers may be able to evolve some fruitful strategies for English teaching that will minimize obstructions and yield better and maximum results.

To this end, we propose that material developers in university education settings have to support EFL classes with ESP materials, choose interesting topic to the students, and give more space to instructors to personalize the learning process and evaluate their own students. Most importantly, English teachers, in the main, must be trained in practical workshops to refine their teaching skills by employing modern technology to facilitate students' learning styles, foster learner-centered approach, and design curriculum in regard with students' profession and future needs.

\section{Conclusion}

Though, lots of efforts have been made to boost the teaching and learning of English in Saudi Arabia, there is still many complaints, ranging from lack of motivation to learn English, lack of suitable English environment, lack of confidence and interest to master and remember English words as well as bored teaching and learning attitude. One way to combat this negativity in language learning is to increase the knowledge and understating of learners so that they can make informed choices about their interest, desire and needs. Material designers in universities have to conduct professional development programs for both English teachers and learners in order to update their knowledge and skills. As for teachers, they have to be aware of the kinds of motivations their students bring with them but they also have to rely on their own power to enhance those motivations and introduce different kinds of strategies which will further develop language learning. If that has been done, the research will expect the following benefits. It will be of value to community since it deals with a universal field of knowledge. To this end, it must be admitted that this study is a human endeavor that must have shortcomings that can be addressed in other studies. In short, drawing on work on motivation in educational contexts there is still much more remain to be done.

\section{References}

Ajibade, Y., \& Ndububa, K. (2008). Effects of word games, culturally relevant songs, and stories on students' motivation in a Nigerian English language class. TESL Canada Journal/ Revue TESL de Canada, 25(2), 27-48.

Al-Maini, Y. (2006). The learning and teaching of English as a foreign language: A case study of a Saudi secondary school. University of East Anglia.

Al-Shammary, E. (1984). A study of Motivation in the learning of English as a foreign language in intermediate and secondary schools in Saudi Arabia. Unpublished PhD thesis, Indiana University.

Bahous, R., Bacha, N., \& Nabhani, M. (2011). Motivating Students in the EFL Classroom: a case study of perspective at Lebanese American University in Lebanon. Canadian Center of Science and Education, 4(3), http:// www.ccsenet.org/elt

Beck, R. C. (2004). Motivation: Theories and principles. Upper Saddle River, N.J.: Pearson Education

Brown, D.H. (2007). Teaching by Principles: An Interactive Approach to Language and Pedagogy. USA: Pearson Publishers

Brown, J.D. (2001). Using surveys in language programs. Cambridge: Cambridge University Press.

Crookes, G., \& Schmidt R.W. (1991). Motivation : Reopening the research agenda. Language Learning, 41(4), 469512.

Dalby, A. (2002). Language in Danger. London: Penguin Books.

Davis, A. (2003). Teachers' and students' beliefs regarding aspects of language learning. Evaluation and Research in Education, 17(4), 207 -216.doi:10.1080/09500790308668303, http://dx.doi.org/ 10.1080/095007903086688303

Dornyei, Z. (2005). The psychology of the language learner. New Jersey: Lawrence Erlbaum Ass. Inc.

Dornyei, Z. (2010a). The relationship between language aptitude and language learning motivation: Individual differences from a dynamic systems perspective. In E. Macaro (Ed.) Continuum companion to second language acquisition (pp. 247-267). London: Continuum. 
Ebata, M. (2008). Motivation factors in language learning. The Internet TESL Journal, 14(4). Retrieved from http://iteslj.org/Articles/Ebata-MotivationFactors.html

El-Dib, M. (2004). Language learning strategies in Kuwait: Links to gender, language level and culture in a hybrid context. Foreign Language Annals, 37 (1), 85 - $95 . \quad$ doi:10.1111/j.19449720.2004.tb02176.x, http://dx.doi.org/10.1111/j.1944-9720.2004.tb02176.x

Feng, R., \& Chen, H. (2009). An analysis on the importance of motivation and strategy in postgraduates English acquisition. English Language Teaching, 2(3), 93-97.

Gangwer, T. (2009). Visual Impact, Visual Teaching: Using Images to Strengthen Learning. Thousand Oaks, CA: Corwin Press.

Gardner, R. C. (1985). Social psychology and second language learning: the role of attitudes and motivation. London: Edward Arnold

Gardner, R. C. and Lambert, W. E. (1972). Attitudes and Motivation in Second Language Learning. Rowley, Mass.: Newbury House.

Guilloteaux, M. J., \& Dornyei, Z. (2008). Motivating language learners: A classroom oriented investigation of the effects of motivational strategies on student motivation. TESOL Quarterly, 42(1), 55-77.

Harmer, J. (1991). The practice of English language teaching - Motivational differences. London: Longman.

Hatch, E. \& Farhady, H. (1982). Research design and statistics. For applied linguistics. Rowley, Mass: Newbury House. Hedge, T. (2000). Teaching and Learning in the Language Classroom. Oxford: Oxford University Press.

Lumsden, L.S. (1994). Student motivation to learn. ERIC Digest, No. 92. Retrieved on April 142011 from www.naeareston.org.

Marshall, C., \& Rossman, G.B. (2006). Designing qualitative research. Thousand Oaks, CA: Sage Publications.

Marshall, H. H. \& Weinstein, R. S. (1986). Classroom context of student-perceived differential teacher treatment. Journal of educational psychology, 78, 441-453.

Masgoret, A. M. and Gardner, R. C. (2003). "Attitudes, motivation, and second language learning :A meta-analysis of studies conducted by Gardner and associates", in Language Learning ,53: 167-210.

Melendy, G. (2008). Motivating writers: The power of choice. The Asian EFL Journal, 10 (3), 187-198. Retrieved from http://www.asian-efl-journal.com/September_08_gm.php

Morell, T. (2004). Interactive lecture discourse for university EFL students. English for Specific Purposes, 23, 325 338. doi:10.1016/S0889-4906(03)00029-2, http://dx.doi.org/ 10.1016/S0889-4906(03)00029-2

Qashoa, S. (2006). Motivation among learners of English in the secondary schools in the eastern coast of the UAE. M.A thesis, British University in Dubai.

Richards, J.C \& Rodgers, T. (1992). Approaches and methods in Language Teaching. United States of America: Cambridge University Press.

Roberts, P. (1958). Understanding English. New York: Harper and Brothers.

Taguchi, T. (2002). Learner factors affecting the use of learning strategies in cross cultural contexts. Prospect, 17(2), 18-34.

Tremblay, P. F., \& Gardner, R. (1995): "Expanding the motivation construct in Language Learning". The Modern Language Journal, 79, 505-519.

Vijchulata, B., \& Lee, G (1985). A survey of students' motivation for learning English. RELC Journal, 16 (1), 68-81.

Wu, W. C. V., \& Wu, P. H. N. (2008). Creating and authentic EFL learning environment to enhance student motivation to study English. Asian EFL Journal, 10(4), 211-226. Retrieved from www.asian-efljournal.com/December_2008_EBook.pdf

Yang, A. \& Lau, L. (2003). Student attitudes to the learning of English at secondary and tertiary levels. System, 31, 107 - 123. doi:10.1016/S0346-251X(02)00076-3, http://dx.doi.org/10.1016/S0346251X(02)00076-3

Yin, R. K. (1994). Case study research: Design and methods (2nd ed.). Thousand Oaks, CA: Sage Publications.

Zhou, A. (2009). What adult ESL learners say about improving grammar and vocabulary in their writing or academic purposes. Language Awareness, 18 (1), 31-46. 
Appendix A (Students' interview questions)

Which skills are emphasized more in your English classes?

In your opinion, what are the objectives of the English classes at the university?

Should English language classes be obligatory or optional?

Do you like the way the classes are taught?

Do you find the time you spend in the classes to be interesting?

Do English language courses meet your needs regarding the use of the English language?

What are three benefits of the English language courses?

Do you think that the English language classes help you cope better with other courses at the university? If yes, how?

What do you like/ dislike about the English language classes?

Appendix B (Teachers' email questionnaire)

Would you answer the following questions related to the teaching/learning of English language classes at the university?

According to you what are the five most important problems that hinder the students' progress in the language classes? According to you what are the two most important strategies to help learners discuss engagingly in the target language? According to you what are the two most important strategies to think deeply in the target language?

According to you what are the two most important strategies to write academically in the target language? 